Journal of Computer Science 8 (4): 482-493, 2012

ISSN 1549-3636

(C) 2012 Science Publications

\title{
Finite Element Analysis of Large Capacity Endplate Steel Connections
}

\author{
${ }^{1}$ Mohamed Eldemerdash, \\ ${ }^{1}$ Taher Abu-Lebdeh and ${ }^{2}$ Moayyad Al Nasra \\ ${ }^{1}$ Department of Civil, Architectural and Environmental Engineering, \\ North Carolina A and T State University, NC 27411, Greensboro \\ ${ }^{2}$ Department of Engineering Technology, West Virginia University, \\ Institute of Technology, Montgomery, WV 25136, USA
}

\begin{abstract}
Problem statement: Extended endplate connection is one of the most widely used beam-to column steel connections because of its fabrication simplicity, good overall performance and cost effectiveness compared with other connection types. The objective of this research is to develop threedimensional finite element models to study the behavior of large capacity eight-bolt extended unstiffened wide endplate steel connections, using current-technology elements instead of legacy elements which were previously used by other researchers. Approach: A finite element software package (ANSYS, version 11.0) was used to create and analyze three finite element models. Two of the finite element models were compared with previously reported experimental results to validate the accuracy of the finite element models. The third model was based on a modification of the second finite element model to improve bolt force distribution. Eight-node brick solid elements were used to model the connection members. The bolt shank was modeled using one three-dimensional spar element that connected the bolt head and nut together. Pretension in bolts, contact algorithm and material nonlinearity were considered in the finite element models. Results: Results of the first and the second finite element models were compared with experimental data. The comparison was based on moment-beam rotation and moment-endplate separation of the finite element models and the corresponding tested specimens. The results of the finite element models were used to compare the behavior of the bolts in the tension region adjacent to the beam bottom flange. Conclusion: The comparison showed good correlations between the finite element models and the corresponding tested specimens which confirmed the validity of the proposed models. Thus, a modified connection was proposed to improve the connection response. A finite element model of the modified connection was modeled, analyzed and compared to the original finite element model prior to modification to show their correlation.
\end{abstract}

Key words: Beam bottom flange, finite element model prior, material nonlinearity, earthquake environments, design alternatives, technology elements instead, corresponding tested spe

\section{INTRODUCTION}

Over the past four decades, steel moment resisting frames have become popular and widely used in steel construction, mainly due to their tremendous energy dissipating characteristics under cyclic loading which represents the ground-shaking and earthquake environments. In January 17, 1994, the Northridge earthquake (6.8 on the Richter scale) struck Los Angeles causing significant wide range damage to various buildings of different heights (Yee et al., 2011;
Yalciner and Hedayat, 2010; Choopool and Boonyapinyo, 2011; Abu-Lebdeh et al., 2011; Aziz and Ching, 2010). Brittle fracture in column webs, column flanges, welds and shear tabs were reported. Most of the reported damage was located within the bottom of the beam flange. Cracks were initiated at welding roots and then extended into the column web and/or flange. The tragedy created the initiative of testing and studying the response of the steel beam-to-column connections. Six full-scale connections were tested at the University of California (Popov et al., 1996) and at

Corresponding Author: Taher Abu-Lebdeh, Department of Civil, Architectural and Environmental Engineering, North Carolina A and T State University, NC 27411, Greensboro 
the University of Texas. The results confirmed the same brittle fracture behavior of the connections. Based on the experimental results, design alternatives were suggested to replace the pre-Northridge connection with post-Northridge connections, which have been tested and shown that they could not entirely eliminate brittle fracture behavior. Further testing was done to investigate the causes of brittle failure in steel connections. As a result of the testing, it was reported that the welders' limited access to the beam bottom flange and the imperfect welding processes resulted in welding discontinuities, which significantly affected the behavior of steel connections (Kaufmann et al., 1997; Rahman et al., 2009; Fard et al., 2010; Hussein, 2011).

Since the 1994 Northridge earthquake, a significant amount of research has been conducted and papers have been published (Fema, 2000; Sherbourne and Bahaari, 2000; Sumner, 2003; Adany and Dunai, 2004; Maggie et al., 2005; Shi et al., 2007; 2008; Yanga et al., 2009; Lamom et al., 2010; Ebrahimi et al., 2010), participating in positive design modifications to improve the behavior of beam-to-column steel connections. Sherbourne and Bahaari (2000) developed three-dimensional finite element models to study the behavior of eight-bolt large capacity extended endplate steel connections. Two endplate thicknesses, 0.75 inch and 1 inch, were considered in their study. For the 1 inch thickness endplate connection, it was reported that the finite element results showed good correlation with the experimental results over the entire loading history. For the 0.75 inch thickness endplate connection, it was reported that the finite element results showed unacceptable correlation with the experimental results, where the model showed about $15 \%$ decrease in initial stiffness and about $50 \%$ decrease in tangent stiffness after yield occurred. Also, the advantages of the hybrid bolted connection versus the two-row bolted connection were discussed and reported that the hybrid bolted connection showed better behavior. Conducted experimental investigations on bolted extended endplate steel connections. The study was made in two parts. In the first part, the objective was to validate the current design procedures for low seismic loading conditions, thus six different multiple row extended endplate steel connections were tested under cyclic loading. Also, analytical models were developed and compared with experimental results. In the second part, seven full-scale eight-bolt wide extended endplate connections, six bare steel beam-to-column connections and one composite slab beam-to-column connections were investigated. They concluded that the developed modified design procedure, conservatively, predicted the connection strength of both configurations. Sumner
(2003) conducted a series of experimental tests on eight-bolt extended endplate steel connections and developed three-dimensional finite models to investigate the column flange bending strength. Six endplate connections were modeled, analyzed and compared with their design procedure. The study included modeling of four-bolt extended endplate beam-to-column stiffened and unstiffened column flange connections, eight-bolt extended stiffened endplate connections and multiple row $1 / 3$ endplate beam-to-column connections. The study of Sumner (2003) reported moment versus endplate separation and column flange response curves. It should be noted that pretension of the bolts was not considered in the study. Adany and Dunai (2004) conducted numerical and experimental analysis on bolted endplate connections subjected to monotonic and cyclic loading. Their study was mainly concentrated on bolted endplate steel-tosteel and base-type steel-to-concrete connections. Geometric, material and contact nonlinearities were considered in the finite element models. Maggie et al. (2005) conducted numerical investigation to study the effect of endplate thickness and connecting bolt diameter on the connection behavior under monotonic loading. Pretensioned $16 \mathrm{~mm}$ and $19 \mathrm{~mm}$ diameter ASTM A325 high-strength steel bolts were used to connect the endplate and the column flange. The study showed extensive prying action and double curvature deformation of the endplate. Maggie and co-researchers reported that the endplate thickness is proportional to the plastic behavior of the connection, while using larger size bolts significantly decreased that effect. Three failure modes were reported as: (1) yield line in endplate, (2) bolt tension failure and (3) combination of both. Shi et al. (2007) proposed an analytical model to evaluate the moment-rotation relationship of bolted stiffened endplate steel connections. Experimental investigation of five different bolted stiffened endplate steel connections subjected to monotonic loading was also conducted. The out-of-plane deformations were restrained during testing and the contact surface between endplate and column flange was prepared by blasting, where friction coefficient of 0.44 was achieved. The results of the experimental tests were used to validate the analytical model, which showed acceptable agreement. Shi et al. (2008) utilized finite element software package (ANSYS) for the modeling of eight different endplate steel connections including flush endplate, stiffened and unstiffened endplate and stiffened and unstiffened column. Different endplate thicknesses, bolt sizes and arrangements were used. Ten-node tetrahedral solid elements (SOLID92) were used to model the entire connection including bolts, 
beam, column and endplate. Pretension section was created in the bolt shank using pretension element (PRETS179). Moreover, material nonlinearity was considered as tri-linear for bolt material and elasticperfectly plastic for all other connection members. The experimental results of Shi et al. (2007) were compared with the results obtained by the finite element of the models. The comparison showed good correlation with average accuracy of $96 \%$. Shi et al. (2008) discussed other outputs from the numerical analysis, which is very difficult to measure during testing. This includes distribution of friction force between the endplate and the column flange and the distribution of principal stresses, which helps in the evaluation of steel connections behavior. Yanga et al. (2009) conducted a series of experimental tests on bolted stiffened and unstiffened extended endplate steel connections, where $\mathrm{H}$-shape beams were connected to endplates by noncomplete penetrated welds. Twenty-four connections were tested under monotonic loading and six connections were tested under cyclic loading to investigate the effect of the non-complete penetrated weld on the behavior of the steel connection. Their monotonic loading tests showed that beam flange local elastic buckling occurred in some connections while plastic buckling occurred in others. Bolts behaved elastically during testing and no weld failure was detected. It was reported that regardless of the type of weld, the connection would exceed the predicted deformation capacity. However, neither the endplate thickness nor the beam inclination had an obvious influence on the connection's ultimate resistance or the behavior of weld. The cyclic loading test was set in three loading levels. During the first level, a little plastic deformation in the beam flange was observed. During the second level, a local buckling in the beam flange in the compression region was observed. During the third level, the compression flange buckled severely. No weld failure was observed in all tests. It was concluded that the weld type had no obvious effect on the connection bearing capacity and the complete penetrated weld had no advantage. Also, Yanga et al. (2009) created finite element models, using the finite element software package (ANSYS), to compare with their experimental results. The results of the finite element models were compared with corresponding experimental results, which showed acceptable agreement.

This study presents the development of threedimensional solid finite element models, to study the behavior of large capacity eight-bolt extended unstiffened wide endplate steel connections, using current-technology elements instead of legacy elements which were previously used by other researchers. Materials were modeled as multilinear materials based on a typical stress-strain curve for each material type. The endplate-beam end connection is taken as perfectly welded. The load was applied as slow incremental rate of vertical displacements to the beam tip. The slow loading rate is adapted to avoid element distortion and to enhance conversion. The finite element results of this study were compared with the experimental results of Sumner et al. (2000) to validate the finite element models. After confirming the accuracy and the validity of the finite element models, a modified connection was proposed to improve the connection response. A finite element model of the modified connection was modeled, analyzed and compared to the original finite element model prior to modification to show their correlation.

Modeling and analysis methodology: As aforementioned, three-dimensional solid finite element models were developed to study the behavior of large capacity eight-bolt extended unstiffened wide endplate steel connections. A finite element software package (ANSYS, version 11.0) was used to create and analyze the finite element models. Eight-node brick solid elements (SOLID185) were used to model the beam, column flange, endplate and bolt heads and nuts. The bolt shank was modeled using one three-dimensional spar element (LINK180) that connected the bolt head and nut together, where rotation was restricted at connecting nodes. The spar element cross-section was set to equal the actual bolt shank cross-section. Pretension in bolt was modeled by defining initial stress state of the spar element to simulate the slip-critical characteristic of the connection. Since the bolts were pretensioned, all coincide nodes that were in common between the bolt heads and the endplate and between the bolt nuts and the column flange were merged and considered in contact at all times. The contact pairs were defined using three-dimensional Target (TARGE170) and Contact (CONTA174) elements to simulate the interface between the endplate and the column flange. It worth noting that the column is considered fully stiffened, thus the column flange was modeled as a rigid member. Applied loads were determined from the vertical displacements applied to the beam tip. Symmetry about the vertical plane passing through the beam/column web was considered and thus half of the connection was modeled and analyzed as shown in Fig. 1. Materials were modeled as multilinear 
materials based on a typical stress-strain curve for each material type: ASTM A36 steel was used for the endplate; ASTM 572 Gr. 50 steel was used for the hot rolled sections; and ASTM A325 steel was used for the high-strength bolts. Materials, geometries and contact algorithm nonlinearities were considered in the proposed model. Surface-to-surface contact separation and the resultant moment were monitored. Also, moment-endplate separation and moment-beam rotation curves were obtained and compared with the experimental results of Sumner et al., (2000). After the solution was done, the General Postprocessor was used to view the analysis results and to plot the deformed shape of the entire model or portion of it.

Boundary conditions, loads, initial states and other significantly important parameters are defined in the solution processor. Parameters were defined properly to allow the simulation to run smoothly as if it was an actual lab test and to avoid localized stresses or false results. For instance, bolt nuts translations were restricted in all directions. Bolt heads translations were restricted in y-direction and bolt shank ends translation in y-direction was restricted so that no rotation is allowed. ANSYS output file was monitored to ensure that the initial stress state was set and defined successfully. The load was applied as slow incremental rate of vertical displacements to the beam tip. The slow loading rate was adapted to avoid element distortion and to enhance conversion. Nodes of interest and their corresponding variables such as contact surfaces separation, beam tip displacements and the resultant forces were monitored at each load step throughout the solution phase to be postprocessed and presented.

Endplate, beam and column flange modeling: Most, if not all, previous finite element analysis, that uses eight-node solid elements for the modeling of connection members, utilized the legacy eight-node structural solid element (SOLID45).

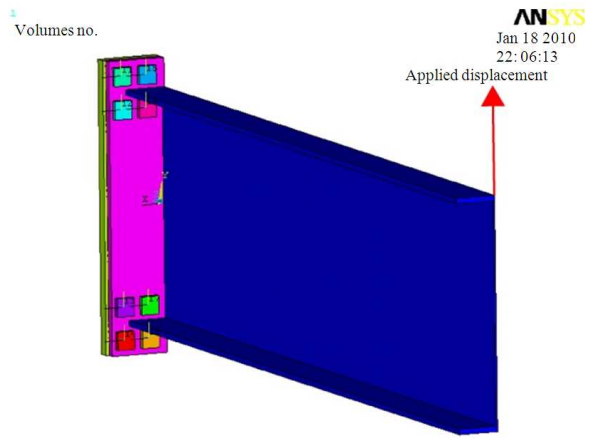

Fig. 1: The symmetry model showing the load direction
In this study, the current-technology homogenous structural eight-node solid elements (SOLID185) were used to model the beam, column flange, endplate and bolt head and nut. The element SOLID185 is defined by eight nodes with three degrees of freedom at each node: translation in $\mathrm{x}, \mathrm{y}$ and $\mathrm{z}$-directions. It has plasticity, hyperplasticity, stress stiffening, creep, large deflection and large strain features.

The beam was meshed in two stages to avoid invalid shape topology. Initially, the area at the beam tip was meshed using four-node quadrilateral elements and then the meshed area was swept along the whole beam length. Mapped mesh was created for the entire beam to enhance results accuracy. Also, proper element aspect ratio of 3:1 was maintained to avoid elements distortion. The beam was entirely meshed with threedimensional hexagonal shape solid elements as indicated in Fig. 2. The endplate and the column flange were meshed entirely with SOLID185, where tetrahedral shape elements were degenerated to adapt the irregularity due to the bolt holes existence as indicated in Fig. 3 and 4. Element edge size was properly managed to ensure proper contact pairs definition when it took place. All coincided nodes between the endplate and the near beam end were merged and considered as perfectly welded.

Surface-to-Surface Contact Modeling: The complex interface between the endplate and the column flange is defined by surface-to-surface contact model. Three-dimensional target element (TARGE170) was used to model the rigid column flange target area. TARGE170 is, generally, used to model threedimensional target surfaces for the corresponding contact elements. The contact elements overlay the solid elements defining the boundary of a deformable body and are potentially in contact with the target surface. The element degrees of freedom depend on the element segment type.

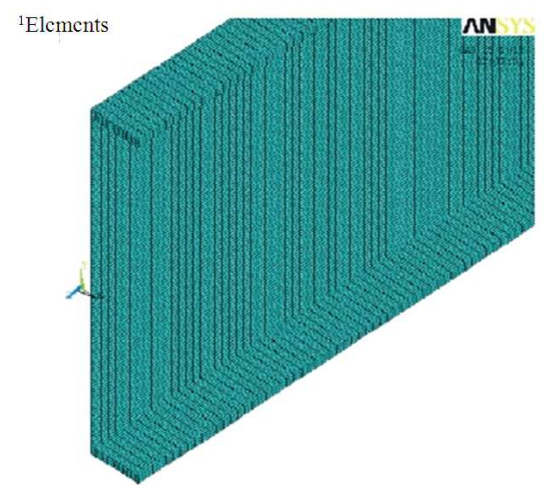

Fig. 2: Beam solid elements 


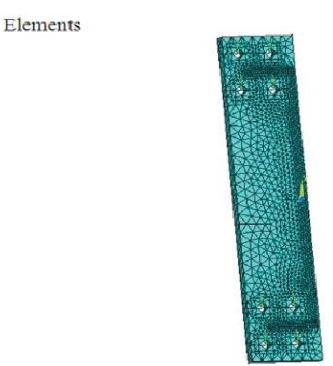

Fig. 3: Endplate solid elements

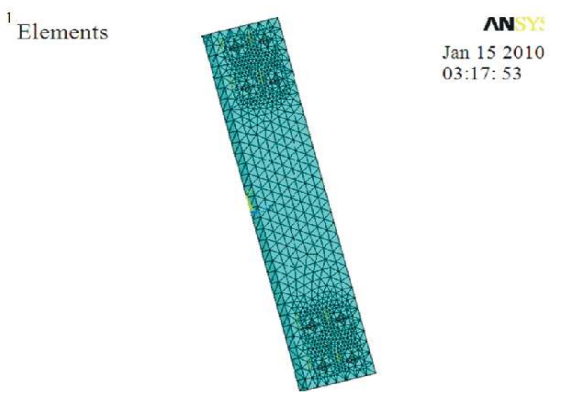

Fig. 4: Column flange solid elements

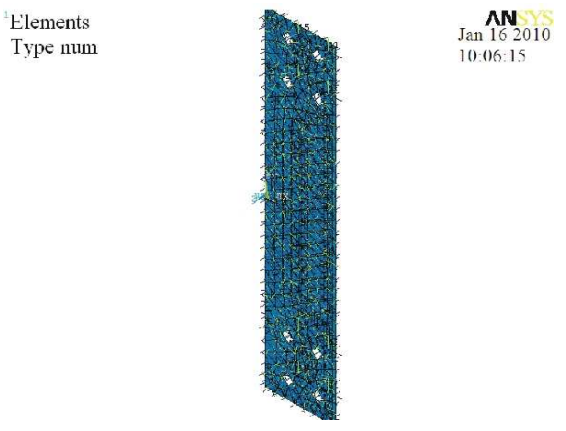

Fig. 5: The Endplate to column flange surface-tosurface contact model

In surface-to-surface contact where areas are used to define both target and contact surfaces, the element has three degrees of freedom at each node.

Three-dimensional contact element (CONTA174) was used to model the flexible endplate contact area as indicated in Fig. 5. CONTA174 is, generally, used to model contact and sliding between three-dimensional target surface and a deformable contact surface. It has the same geometric characteristics as the underlying solid element face with which it is connected. The contact occurs when the contact elements penetrate one of the target segment elements on a particular target surface. The element allows Coulomb friction, shear stress friction, or user-defined friction. Also, the element allows separation of bonded contact to simulate the interface delamination.

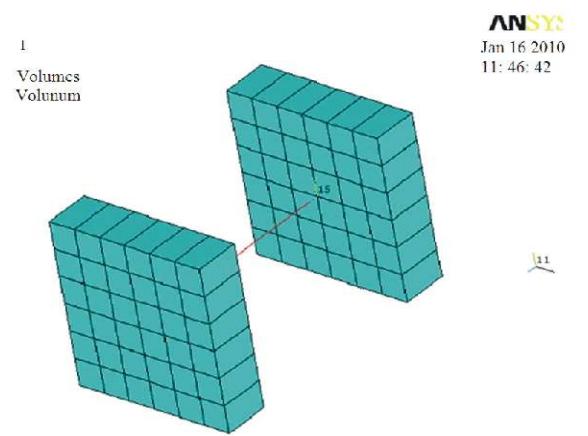

(a)

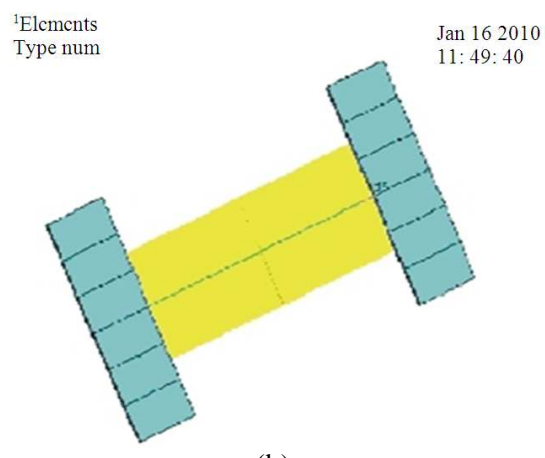

(b)

Fig. 6: Bolt modeled parts (a) Solid and line elements (b) Size-scaled elements

It should be noted that a friction coefficient of 0.5 is defined herein to simulate slipping action between the contact surfaces.

Bolt and pretension modeling: The bolt head and nut were modeled using the same solid element (SOLID185) that was used for the endplate, beam and column flange. The bolt shank was modeled using the current-technology three-dimensional spar element (LINK 180). The spar element cross-sectional area is defined to be equal to the actual bolt shank crosssectional area. This spar element is used herein to connect the bolt head and nut together as shown in Fig. 6 . It is worth noting that an initial stress state was assigned to the spar element to model the pretension action in the bolts. The applied pretension force values were defined in accordance with the AISC Steel Construction Manual (13th Edition) recommendations for minimum required pretension for high-strength steel structural bolts. Vertical displacement and rotation were restricted for the spar element nodes. It should be noted that LINK 180 is a three-dimensional uniaxial tensioncompression line element, defined by two nodes with three degrees of freedom at each node: translation in the nodal $\mathrm{x}, \mathrm{y}$ and $\mathrm{z}$-directions. The Element has plasticity, creep, rotation, large deflection and large strain 
features. It supports elasticity, isotropic hardening plasticity, kinematics hardening plasticity and nonlinear hardening plasticity. Also, it allows a change in crosssection as a function of axial elongation while the overall volume of the link element is kept constant.

\section{MATERIALS AND METHODS}

The materials were modeled using multilinear isotropic hardening material models that use Von Mises yield criteria coupled with an isotropic work hardening assumption. Material behavior is described by an actual true stress-strain curve shown in Fig. 7. The initial slope of the curve is taken as the elastic modulus of elasticity (E) which underneath is the material elastic region. When the material reaches the yield stress, the curve continues along a curve defined by a number of linear segments that represent the material plastic region. ASTM A36 steel was used to model endplate material; while ASTM A572 Gr. 50 steel was used for the beam and the column flange and ASTM A325 steel for bolts. The true stress $\left(\sigma_{\mathrm{e}}\right)$ and the true strain $\left(\varepsilon_{\mathrm{t}}\right)$ are functions of the engineering stress $\left(\sigma_{\mathrm{e}}\right)$ and strain $\left(\varepsilon_{\mathrm{t}}\right)$. The values of the true stress and the true strain are calculated from equation (1) and equation (2) respectively. The two equations are used to convert the engineering stress-strain curve and a true stress-natural strain curve, which is used to define the multilinear material data tabulated in ANSYS.

The general postprocessor: After the model is built in the Preprocessor and the solution was successfully executed, the nodal and element solutions were used to display the effect of the load in the entire finite element model or just a portion of the model as shown in Fig. 8 . Both nodal and element solutions were used to obtain tabular data of contact pairs separation, displacements and reactions. The tabular data were used to calculate beam rotation $(\theta)$ and applied moment.

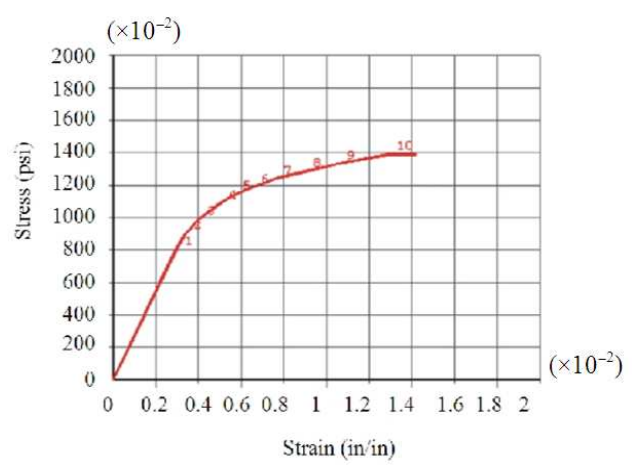

Fig. 7: The Bolts Material (ASTM A325) Model in ANSYS

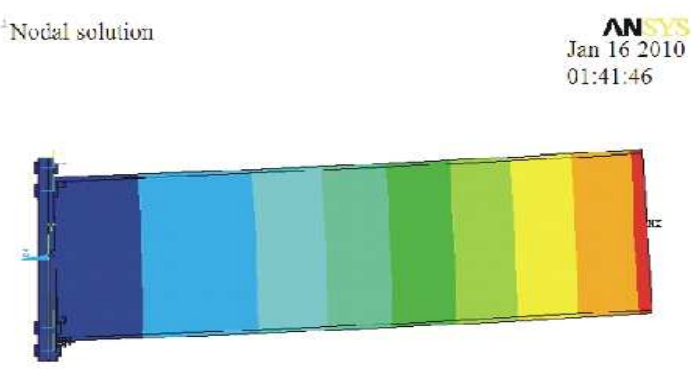

(a)

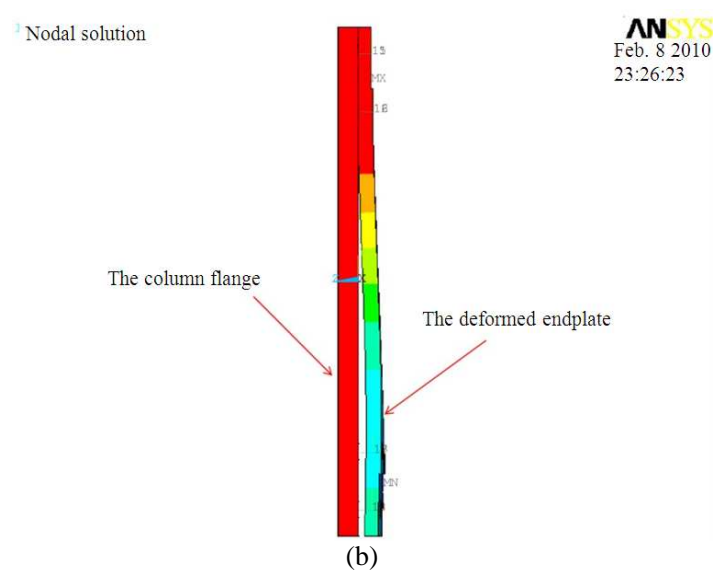

Fig. 8: Contour plots of the entire model and a portion of the model (a) Vertical displacement of the entire model (b) Endplate/Contact pairs separation

Both tabular data and the calculated values were used to generate moment-endplate separation and momentbeam rotation curves to be compared with actual experimental results and to validate the finite element model as discussed in the following sections.

Validation of the finite element models: Experimental results from testing of eight-bolt unstiffened extended wide endplate steel connections conducted by Sumner et al. (2000) were used to validate the proposed finite element models. The tests were conducted at Virginia Polytechnic Institute and State University and sponsored by SAC Phase 2 Steel Project. Two test specimens were considered for finite element analysis. Each specimen consisted of a W14×193 column, a W30 $\times 99$ beam, a total of sixteen high-strength steel 1.25 inch diameter bolts and an endplate of 1.125 inch thickness for the first specimen and 1 inch thickness for the second specimen. Continuity plates and a doubler plate of 0.75 inch and 0.375 inch thickness respectively, were used to reinforce the column. 


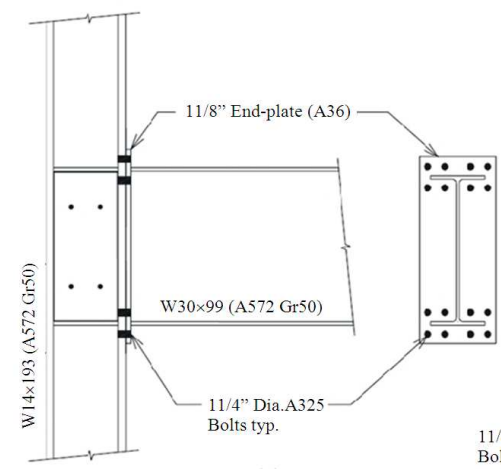

(a)

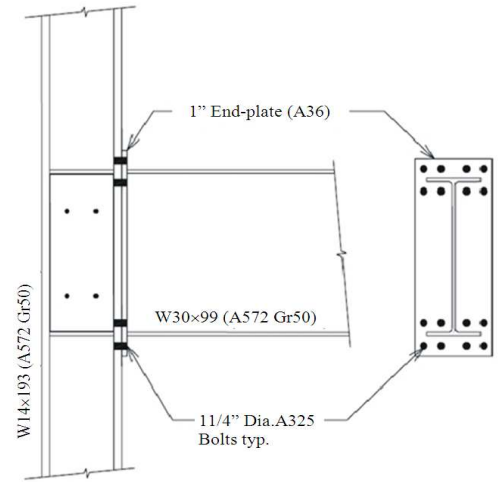

(b)

Fig. 9: Connection Configurations (Sumner et al., 2000) (a) First Specimen (8E-4W-1.25-1.12530) (b) Second Specimen (8E-4W-1.25-1-30)

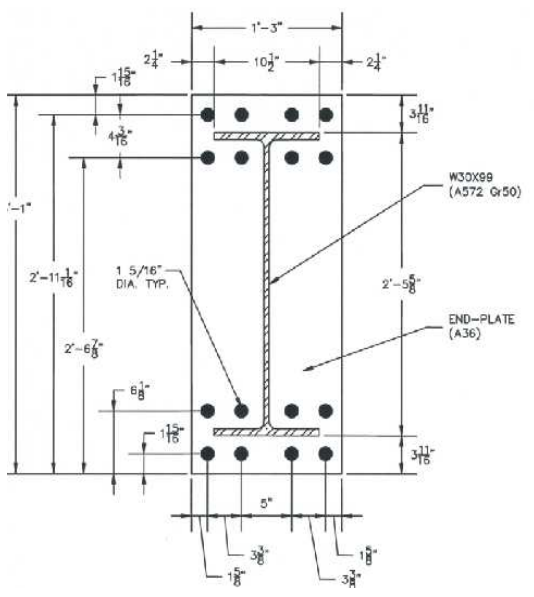

Fig. 10: Endplate Layout (Sumner et al., 2000)

ASTM A572 Gr. 50 steel was used for the hot rolled sections; ASTM A36 steel was used for the endplate, the continuity plates and the doubler plate; and ASTM A325 steel was used for the bolts. The connection configurations and the endplate layout are illustrated in Fig. 9 and 10 respectively.

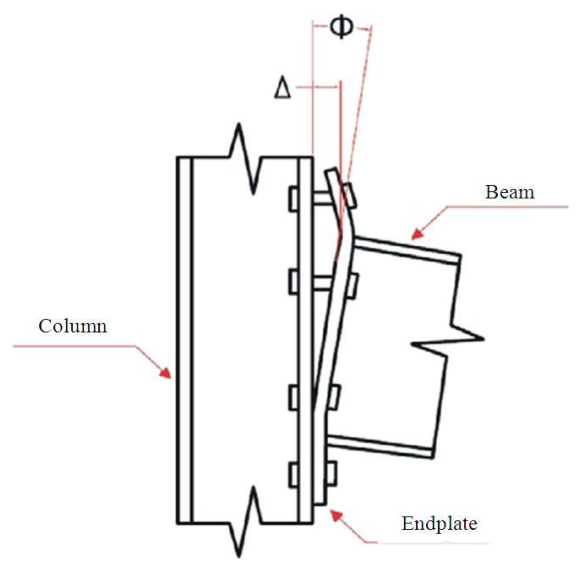

Fig. 11: Endplate separation and rotation

The joint rotation (endplate rotation) is defined as the relative rotation between the beam top and bottom flanges adjacent to the endplate. The endplate rotation $(\phi)$ in the finite element model Fig. 11 was taken as the ratio of the endplate separation $(\nabla)$ at the tension region to the distance between the beam top flange centerline and the beam bottom flange centerline. The endplate separation and rotation are illustrated in Fig. 11.

\section{RESULTS}

The experimental test results of moment-beam rotation and moment-endplate separation of the first specimen (8E-4W-1.25-1.125-30) and second specimen (8E-4W-1.25-1-30) were used to validate the corresponding finite element results. Comparison of the results is shown in Fig. 12 and 13. The moment-beam rotation curves showed that the finite element model had less initial rotation stiffness (slope of the linear portion of the curve) than the tested connection by an average of $3 \%$ in the first specimen and $1.5 \%$ in the second specimen, while the tangential rotation stiffness (after yield) of the finite element model was almost the same as the tested connection. The moment-beam rotation curves also showed that the finite element model had less moment capacity than the tested connection. The finite element model behavior was almost linear when subjected to moment up to $1200 \mathrm{ft}-$ kips in the first specimen and $1170 \mathrm{ft}$-kips in the second, while the tested connection behavior was almost linear when subjected to moment up to $1280 \mathrm{ft}$ kips in the first specimen and $1220 \mathrm{ft}$-kips in the second specimen. On the other hand, moment-endplate separation curves Fig. $12 \mathrm{~b}$ and $13 \mathrm{~b}$ showed that the finite element model is in very good correlation with the tested connection, where both curves followed almost the same trend. 


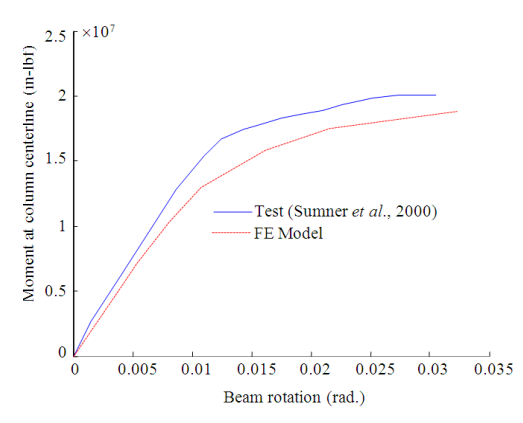

(a)

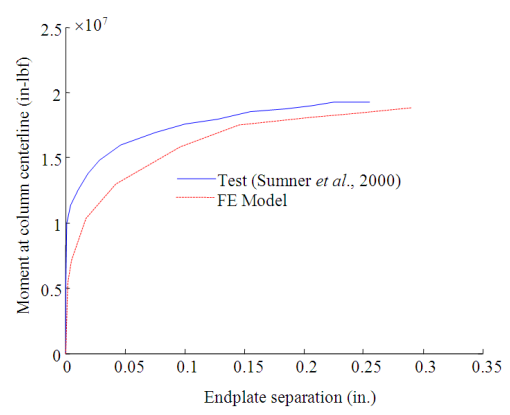

(b)

Fig. 12: Comparison between the FE Model and the Test Results (Specimen 1) (a) Moment-Beam Rotation Curves (b) Moment-Endplate Separation Curves

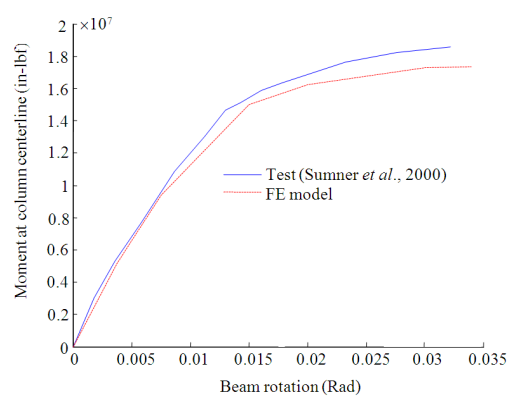

(a)

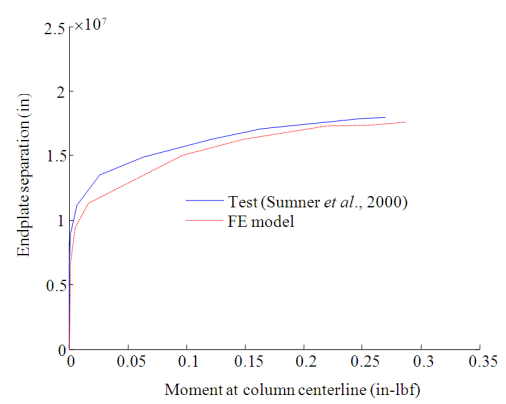

(b)

Fig. 13: Comparison between the FE Model and Test the Results (Specimen 2) (a) Moment-Beam Rotation Curves (b) Moment-Endplate Separation Curves

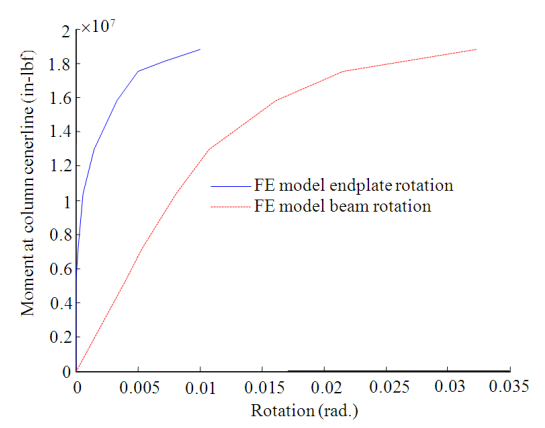

(a)

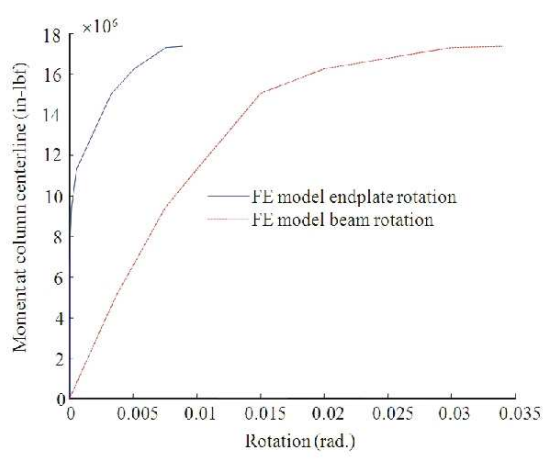

(b)

Fig. 14: FE Model endplate rotation Vs beam rotation (a) Specimen 1(b) Specimen 2

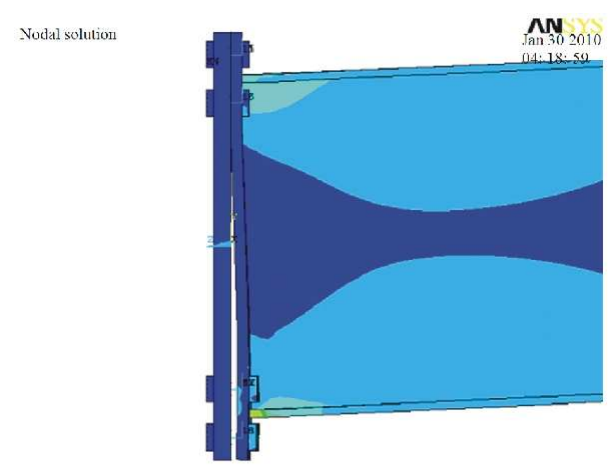

(a)

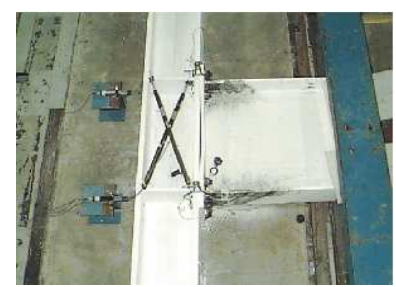

(b)

Fig. 15: Comparison of the Endplate Deformation (Specimen 1) (a) The Deformed Shape of the Endplate after simulationThe Deformed Shape of the Endplate after testing (Sumner et al., 2000) 


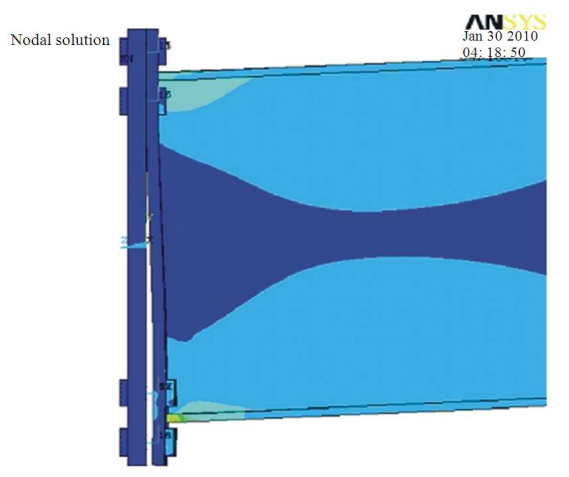

(a)

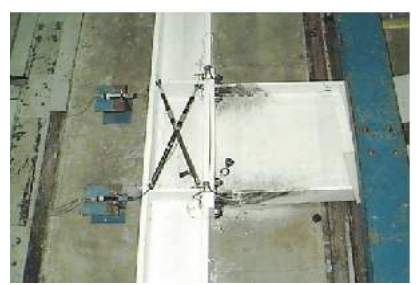

(b)

Fig. 16: Comparison of the Endplate Deformation (Specimen 2) (a) The Deformed Shape of the Endplate after simulation (b) The Deformed Shape of the Endplate after testing (Sumner et al., 2000)

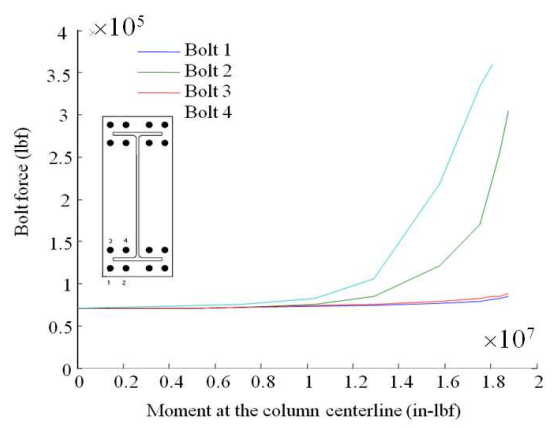

(a)

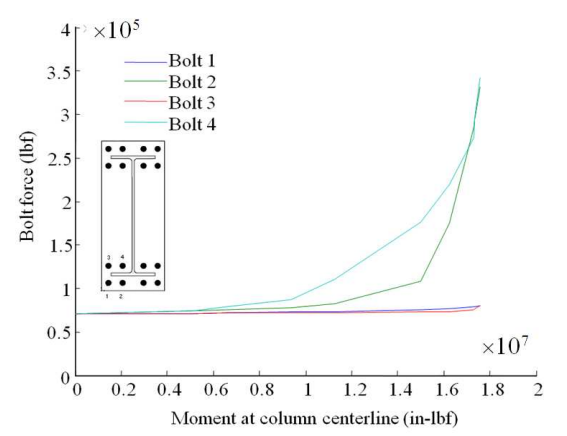

(b)

Fig. 17: Variation of the Forces of the Bolts in the Tension Region (a) Specimen 1 (b) Specimen 2
The finite element results were used to compare the endplate rotation with the beam rotation Fig. 14. The comparison showed that the endplate has higher initial rotation stiffness than the beam, but the beam has larger ductility and rotation capacity than the endplate as indicated in Fig. 14. The comparison also showed that the endplate and the beam had the same moment capacity values.

Additionally, an image of the connection after testing was compared to an image of the connection after simulation to show the correlation between the lab test and the simulation of the endplate deformation due to the applied load. The comparison between the two images showed very good correlation between the finite element model and the tested connection as indicated in Fig. 15 and 16. Finally, the results of the finite element model were used to obtain the bolt force-moment curves, which were used to show the behavior of the four bolts based on their layout in the tension region adjacent to the bottom beam flange, as indicated in Fig. 17.

\section{DISCUSSION}

In Figure 12 and 13, the initial rotation stiffness is the slope of the linear portion of the curve. It may be compared with the flexural stiffness of the beam $\left(E_{b}\right.$ $\left.1_{b} / L_{b}\right)$. Thus, the connection might be classified as rigid, semi-rigid and pinned based on its initial stiffness.

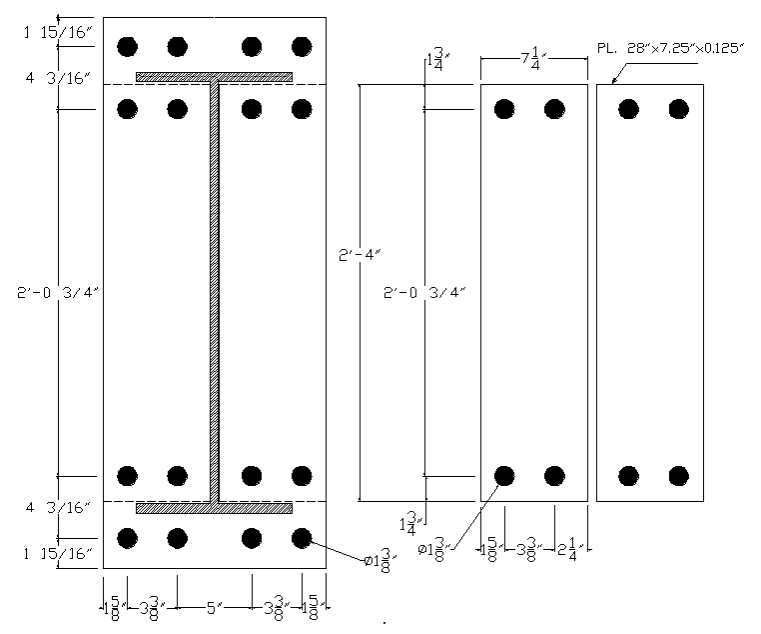

Fig. 18: The Proposed shims and endplate layout

In the Euro code 3 (2002), the connection is rigid when the initial stiffness is larger than twenty-five times the beam flexural strength $\left(25 \mathrm{E}_{\mathrm{b}} \mathrm{l}_{\mathrm{b}} / \mathrm{L}_{0}\right)$, pinned when the initial stiffness is less than half the beam flexural strength $\left(0.5 \mathrm{E}_{b} \mathrm{l}_{\mathrm{b}} / \mathrm{L}_{0}\right)$, semi-rigid when the initial stiffness is in between of these two values. 


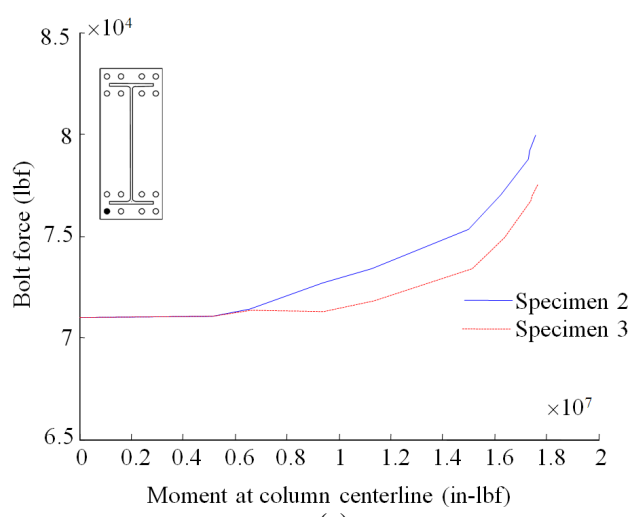

(a)

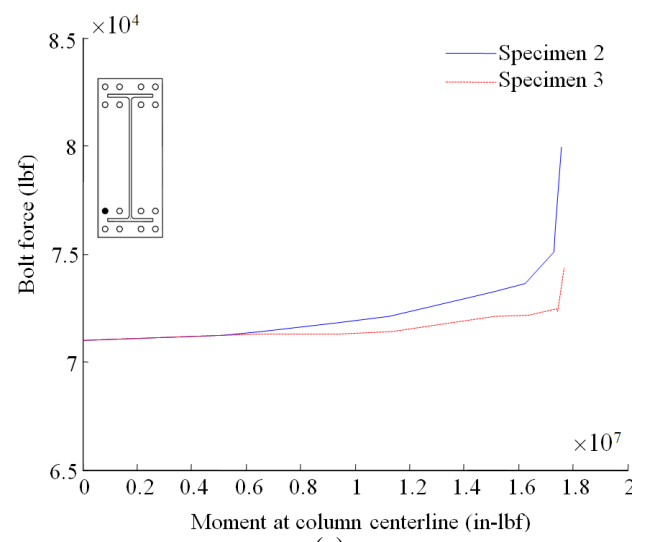

(c)

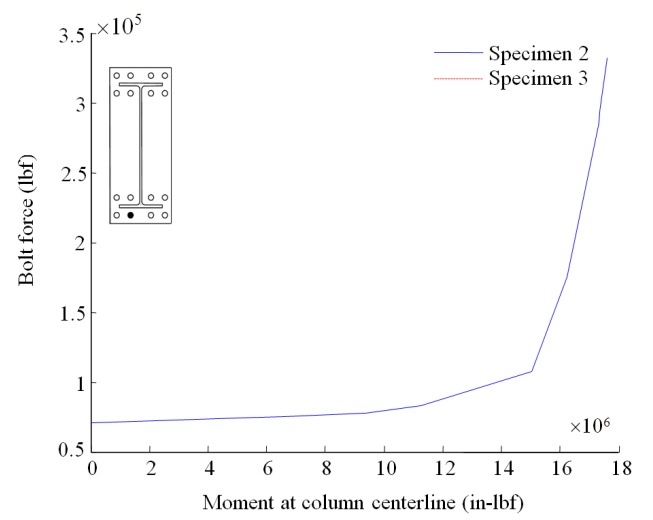

(b)

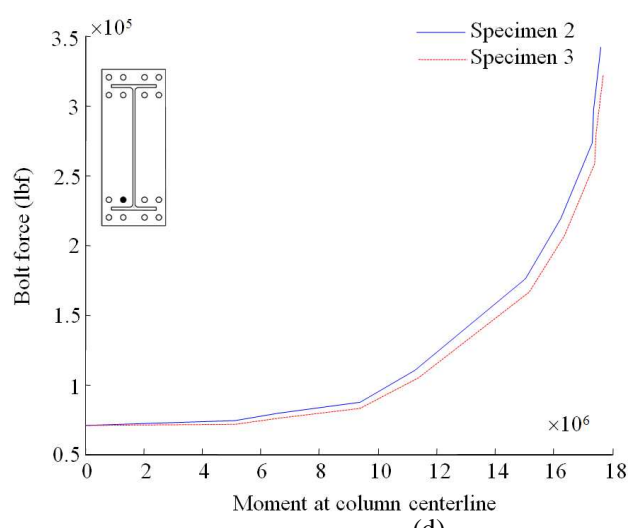

(d)

Fig. 19: Comparison between the FE Models of Specimen 2 and Specimen 3: Moment-Bolt Force Curves (a) Bolt 1 (b) Bolt 2 (c) Bolt 3 (d) Bolt 4

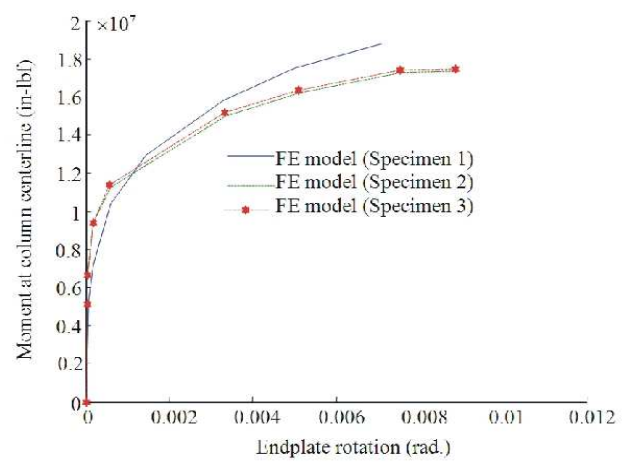

Fig. 20: Moment-endplate rotation curves of the finite element models

The comparison between the results of the finite element model and the experimental test Fig. 12 and 13 showed overall acceptable correlations. The finite element moment-beam rotation curve followed the same trend as the test results as well as the momentendplate separation curve.

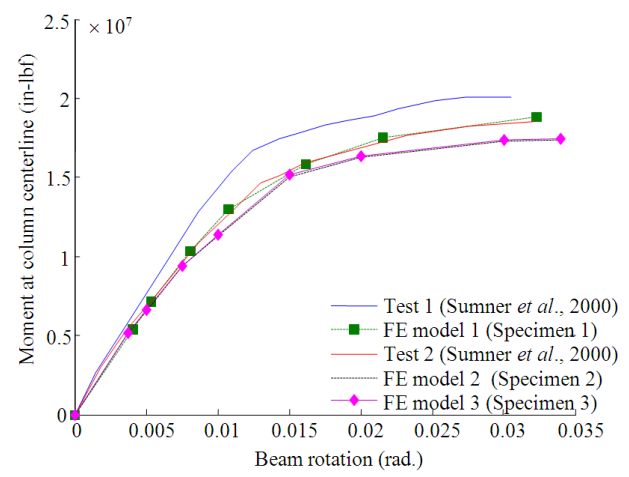

Fig. 21: Moment-beam rotation curves of the finite element models

As indicated in Fig. 17, the comparison between the four bolts in the tension region showed that the bolt force was initially distributed almost equally among all four bolts in the tension region till the connection reached about $50 \%$ of its total moment capacity. 
Thereafter, the inner bolts (bolt 2 and bolt 4) were subjected to significantly larger forces than the outer bolts (bolt 1 and bolt 3 ). The inner bolt adjacent to the beam web (bolt 4) developed the highest force value at remarkably lower applied moment, when compared with the other bolts in the tension region. The developed high force indicated possible fracture failure of bolt 4 first while the outer bolts (bolt 1 and bolt 3 ) are in their elastic comfort zone. The inner bolts (bolt 2 and bolt 4) of the second specimen had almost the same plastic behavior when the tension bolt force exceeded 250 kips. The overall comparison between the finite element results and the test results verified the accuracy of the finite element model.

The second specimen was modified to improve bolt force distribution, especially for the inner bolts adjacent to the beam web. The modification was based on strengthening the endplate in the region between the beam top and bottom flanges. Two thin plates of 287.5 0.125 inch were used to strengthen the endplate and to distribute the bolt forces better. The thin plates (shims) are made of ASTM A36 steel and attached to the endplate by the connecting bolts as indicated in Fig. 18. A three-dimensional finite element model was created and analyzed to study the behavior of the modified connection. The results of the finite element model of the modified connection (specimen 3) were compared to the finite element model of specimen 2. Results of moment-beam rotation showed that specimen 3 had slightly higher moment capacity than specimen 2 by $0.7 \%$, which means that the attached shims had little or no influence on the connection moment capacity. On the other hand, the bolt forces were monitored closely for each bolt in the tension region adjacent to the beam bottom flange to study the effect of the attached shims on the bolt forces distribution. Moment-bolt force curves were obtained for each bolt in the tension region to compare between the modified connection (specimen 3) and specimen 2, as shown in Fig. 19. The comparison between the two specimens showed that bolt 1 and bolt 2 developed forces reduction of 3 and $2 \%$ respectively, while bolt 3 and bolt 4 developed forces reduction of 7 and $8 \%$ respectively, due to installation of the shims in specimen 3. Apparently, the bolts attached to the shim (bolt 3 and bolt 4 ) benefited more than the bolts below the beam bottom flange (bolt 1 and bolt 2) which were not attached to the shim.

Results of the finite element models were used to compare the endplate rotation for all three specimens as indicated in Fig. 20. The comparison showed that both specimen 2 and specimen 3 had relatively higher initial rotation stiffness than specimen 1 , while specimen 1 had higher tangential rotation (after yield) than both specimen 2 and specimen 3. The comparison also showed that specimen 1 had remarkably higher moment capacity than the other two specimens, but it had less rotation capacity when compared with the rotation capacity of the other two specimens. Further, momentbeam rotation curves of the tested connections were compared with the three finite element models to show their correlation as indicated in Fig. 21. Specimen 1 shows higher moment capacity when compared to the moment capacity of the other two specimens. But the beam rotation capacity of the specimen 1 was relatively less than specimen 2 and specimen 3.

\section{CONCLUSION}

Due to the high cost of steel connection materials, fabrication and testing; and since steel connection testing is a destructive test, it is important to predict the failure modes and connection behavior using finite element analysis. This research focused on threedimensional finite element modeling and analysis of large capacity eight-bolt unstiffened extended wide endplate steel connections. The objective of the research was to develop three finite element models that could predict the steel connections behavior. Results of the first and the second finite element models were compared to experimental results of tests conducted by Sumner et al. (2000) to validate and confirm the accuracy of the finite element models. The comparison showed good correlations between the finite element models and the corresponding tested specimens which confirmed the validity and the accuracy of the finite element models. The second finite element model (specimen 2) was modified to improve bolt force distribution which contributed in reduction of the bolt forces, especially for the bolts above the beam bottom flange. The results of the finite element model of the modified connection were compared to the results of the second finite element model (specimen 2) to study the effect of the modification on the behavior of the modified connection. The comparison showed that the bolts above the beam bottom flange of the modified connection developed forces less than the second specimen by $8 \%$ suggesting that the proposed modification improved the bolt forces distribution and reduced the developed bolt forces without affecting the overall performance of the entire connection. From the results of this research, the following conclusions may be drawn:

- The inner bolts in the tension region develop remarkably higher bolt forces than the outer bolts in the tension region, which indicates possible bolt fracture of the inner bolts 
- Strengthening the endplate using the thin plates improves bolt force distribution, which may be a possible remedy to prevent bolt fracture at early loading stage

- In the modified connection, the bolts above the beam bottom flange have reduction in bolt force by $8 \%$ due to better bolt force distribution

- Since all the parameters defined in the finite element program are considered ideal and free from any defects or discontinuities, the finite element modeling and analysis will always be used as a tool to predict the behavior of a specimen not to evaluate it. The finite element analysis will not replace the experimental testing, but complements it

\section{ACKNOWLEDGEMENT}

The researchers would like to graciously thank the Defense Threat Reduction Agency (DTRA) for funding of this research.

\section{REFERENCES}

Abu-Lebdeh, T., S. Hamoush, W. Choi and M. Al Nasra, 2011. High Rate-Dependent Interaction Diagrams for Reinforced Concrete Columns. Am. J. Eng. Applied Sci., 4: 1-9. DOI: 10.3844/ajeassp.2011.1.9

Adany, S. and L. Dunai, 2004. Finite element simulation of the cyclic behaviour of end-plate joints. Com. Struct., 82: 2131-2143. DOI: 10.1016/j.compstruc.2004.03.062

Aziz, Z.A. and D.L.C. Ching, 2010. The role of sine and cosine components in love waves and rayleigh waves for energy hauling during earthquake. Am. J. Applied Sci., 7: 1550-1557. DOI: 10.3844/ajassp.2010.1550.1557

Yanga, K.C., S.J. Chenb, M.C. Hoc, 2009. Behavior of beam-to-column moment connections under fire load. J. Constructional Steel Res., 65: 1520-1527. DOI: 10.1016/j.jcsr.2009.02.010

Choopool, N. and V. Boonyapinyo, 2011. Seismic performance evaluation of reinforced concrete moment resisting frames with various ductility in low seismic zone. Am. J. Eng. Applied Sci., 4: 1736. DOI: 10.3844/ajeassp.2011.17.36

Ebrahimi, M., H. Sharifian and M. Ahangar, 2010. Seismic response evaluation of moment resistant frame with built-up column section. Am. J. Eng. Applied Sci., 3: 37-41. DOI: 10.3844/ajeassp.2010.37.41

Fard, A.K. Mohd, H. Ahmad and D.R. Ossen, 2010. Cultural identity expressions through visual analysis in post-disaster housing. Am. J. Applied Sci., 7: 1412-1419. $\quad$ DOI: 10.3844/ajassp.2010.1412.1419
Fema, F., 2000. Recommended seismic design criteria for new steel moment-frame buildings. Federal Emergency Management Agency.

Hussein, A.T., 2011. Elastic-Plastic non linear behaviors of suddenly loaded structures. Am. J. Eng. Applied Sci., 4: 89-92. DOI: 10.3844/ajeassp.2011.89.92

Kaufmann, E. J., F.J.W. DiJulio, R.M., Jr. J.L. Gross, 1997. Failure Analysis of Welded Steel Moment Frames Damaged in the Northridge Earthquake. The National Institute of Standards and Technology.

Lamom, A., T. Thepchatri and W, Rivepiboon, 2010. Hybrid connection simulation using dynamic nodal numbering algorithm. Am. J. Applied Sci., 7: 1174-1181. DOI: 10.3844/ajassp.2010.1174.1181

Maggie, Y.I., R.M. Goncalves, R.T. Leon and L.F.L Ribeiro, 2005. Parametric analysis of steel bolted end plate connections using finite element modeling. J. Constructional Res., 61: 689-708. DOI: 10.1016/j.jcsr.2004.12.001

Yee, P.T.L., A.B. Adnan, A.K. Mirasa and A.B.A. Rahman, 2011. Performance of IBS precast concrete beam-column connections under earthquake effects: A literature review. Am. J. Eng. Applied Sci., 4: 93-101. DOI: 10.3844/ajeassp.2011.93.101

Popov, E.P., M. Blondet, L. Stepanov and B. Stojadinovic, 1996. Experimental investigations of beam-column subassemblies. SAC.

Rahman, M.M., A.B. Rosli, M.M. Noor, M.S.M. Sani and J.M. Julie, 2009. Effects of spot diameter and sheets thickness on fatigue life of spot welded structure based on fea approach. Am. J. Applied Sci., 6: 137-142. 10.3844/ajassp.2009.137.142

Shi, G., Y. Shi, Y. Wang and M.A. Bradford, 2008. Numerical simulation of steel pretensioned bolted end-plate connections of different types and details. Eng. Struct., 30: 2677-2686. DOI: 10.1016/j.engstruct.2008.02.013

Shi, Y., G. Shi and Y. Wang, 2007. Experimental and theoretical analysis of the moment-rotation behaviour of stiffened extended end-plate connections. J. Constructional Steel Res., 63: 12791293. DOI: $10.1016 /$ j.jcsr.2006.11.008

Sumner, E.A., 2003. Unified Design of extended endplate moment connections subject to cyclic loading. Ph.D. Thises, Virginia Polytechnic Institute State University.

Yalciner, H. and A.A. Hedayat, 2010. Repairing and strengthening of an existing reinforced concrete building: A north cyprus perspective. Am. J. Eng. Applied Sci., 3: 109-116.DOI: 10.3844/ajeassp.2010.109.116

Sumner, M., 2000. Risk factors in enterprise-wide/ERP projects. J. Inform. Technol., 15: 317-327. DOI: $10.1080 / 02683960010009079$ 